\title{
Enhanced K-Edge Radiography Using a High-Spatial-Resolution Cadmium Telluride Array Detector
}

\section{Manabu Watanabe1, Eiichi Sato ${ }^{2 *}$, Yasuyuki Oda², Hodaka Moriyama1, Osahiko Hagiwara1, Hiroshi Matsukiyo1, Toshiyuki Enomoto1, Shinya Kusachi' ${ }^{1}$}

\author{
${ }^{1}$ Department of Surgery, Toho University Ohashi Medical Center, Meguro, Japan \\ ${ }^{2}$ Department of Physics, Iwate Medical University, Yahaba, Japan \\ Email: *dresato@iwate-med.ac.jp
}

How to cite this paper: Watanabe, M., Sato, E., Oda, Y., Moriyama, H., Hagiwara, O., Matsukiyo, H., Enomoto, T. and Kusachi, S. (2018) Enhanced K-Edge Radiography Using a High-Spatial-Resolution Cadmium Telluride Array Detector. International Journal of Medical Physics, Clinical Engineering and Radiation Oncology, 7, 296-307.

https://doi.org/10.4236/ijmpcero.2018.73024

Received: May 8, 2018

Accepted: July 15, 2018

Published: July 18, 2018

Copyright $\odot 2018$ by authors and Scientific Research Publishing Inc. This work is licensed under the Creative Commons Attribution International License (CC BY 4.0).

http://creativecommons.org/licenses/by/4.0/ c) (i) Open Access

\begin{abstract}
To confirm the imaging effect of a dual-energy (DE) cadmium telluride (CdTe) array detector (XCounter, Actaeon) and to perform fundamental studies on DE computed tomography, we performed enhanced K-edge radiography using iodine (I) and gadolinium (Gd) media. DE radiography was performed using an X-ray generator with a $0.1-\mathrm{mm}$-diam-focus tube and a 0.5-mm-thick beryllium window, a 1.0-mm-thick aluminum filter for absorbing extremely low-energy photons, and the CdTe array detector with pixel dimensions of $0.1 \times 0.1 \mathrm{~mm}^{2}$. Each pixel has a charge-sensitive amplifier and a dual-energy counter, and the event pulses from the amplifier are sent to the counter to determine two threshold energies. The tube current was a maximum value of $0.50 \mathrm{~mA}$, and the tube voltages for I- and Gd-K-edge radiograms were 60 and $80 \mathrm{kV}$, respectively. In the I-K-edge radiography of a dog-heart phantom at an energy range of $33-60 \mathrm{keV}$, the muscle density increased, and fine coronary arteries were visible. Utilizing Gd-K-edge radiography of a rabbit head phantom at an energy range of $50-80 \mathrm{keV}$, the muscle density increased, and fine blood vessels in the nose were observed at high contrasts. Using the DE array detector, we confirmed the image-contrast variations with changes in the threshold energy.
\end{abstract}

\section{Keywords}

X-Ray Photon Counting, CdTe-Array Detector, Dual-Energy, Energy-Dispersive Radiography, I-K-Edge Radiography, Gd-K-Edge Radiography

\section{Introduction}

Monochromatic parallel beams are produced using a synchrotron in conjunction 
with single silicon crystals, and the clean beams with energies approximately 35 $\mathrm{keV}$ have been applied to perform enhanced K-edge angiography [1] [2] using iodine (I) contrast media. Therefore, we developed a cerium (Ce) X-ray generator [3] to perform I-K-edge angiography using cone beams; quasi-monochromatic Ce-K photons are absorbed effectively by I atoms.

Enhanced K-edge angiography could also be performed utilizing photon-counting energy-dispersive (ED) method, and the angiography was carried out using an ED camera [4]. In addition, an X-ray fluorescence camera [5] was developed to map I and gadolinium (Gd) atoms in the living bodies.

Recently, we have developed several first-generation ED computed tomography (CT) scanners [6] [7] [8] to perform K-edge CT. Using dual- and quad-energy ED-CT scanners with high-energy-resolution cadmium telluride (CdTe) detectors, K-edge tomograms using I and Gd media are obtained simultaneously at spatial resolutions of $0.5 \times 0.5 \mathrm{~mm}^{2}$. Subsequently, CdTe array detectors [9] [10] have been developed to perform preclinical ED-CT scanners, and we are also constructing a high-spatial-resolution ED-CT scanner using an array detector [11]. Therefore, we have to confirm the imaging effects of the array with changes in the tube voltage and the threshold energy.

In our research, our major objectives are as follows: to perform K-edge angiography (radiography), to confirm the contrast variations with changes in the threshold energy, and to improve the image quality by averaging the 200 frames. Therefore, we performed the enhanced K-edge radiography using a novel dual-energy (DE) CdTe array detector using I and Gd media.

\section{Methods}

\subsection{DE Radiography}

Figure 1 shows an experimental setup for photon-counting radiography using a DE CdTe array detector (XCounter, Actaeon), and the radiographic conditions are shown in Table 1. The X-ray generator (Rtech, RXG-0120) has a 0.1-mm-diam-focus tube with a 0.5 -mm-thick beryllium window and produces extremely low-energy photons. Therefore, a 1.0-mm-thick aluminum ( $\mathrm{Al}$ ) filter is used to absorb low-energy photons and to reduce the incident dose for objects. The distance between the X-ray source and the array detector is $1.00 \mathrm{~m}$, and the object is attached to the detector to decrease the magnification ratio.

The tube current was regulated to the maximum value of $0.50 \mathrm{~mA}$ to increase the count rate for DE radiography. Using I-based contrast media, the tube voltage was $60 \mathrm{kV}$, and the threshold energies were 10 and $33 \mathrm{keV}$. On the other hand, the threshold energies were 30 and $50 \mathrm{keV}$ using Gd media, and the tube voltage was $80 \mathrm{kV}$. The K-edge energies of I and Gd are 33.2 and $50.2 \mathrm{keV}$, respectively, and $\mathrm{X}$-ray photons with energies just beyond the K-edge energies are absorbed effectively by the contrast media.

The maximum frame rate increases with increasing dose rate, and the frame rate for the DE radiography was determined as 100 frames per second (fps). 


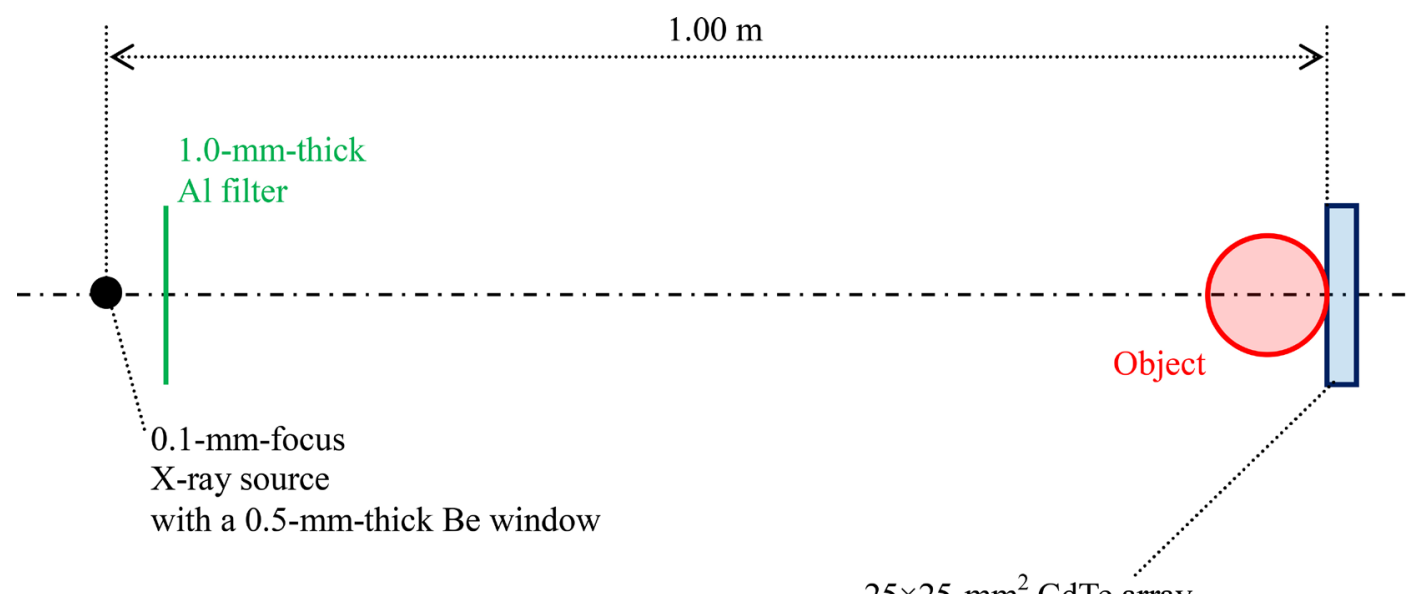

$25 \times 25-\mathrm{mm}^{2} \mathrm{CdTe}$ array

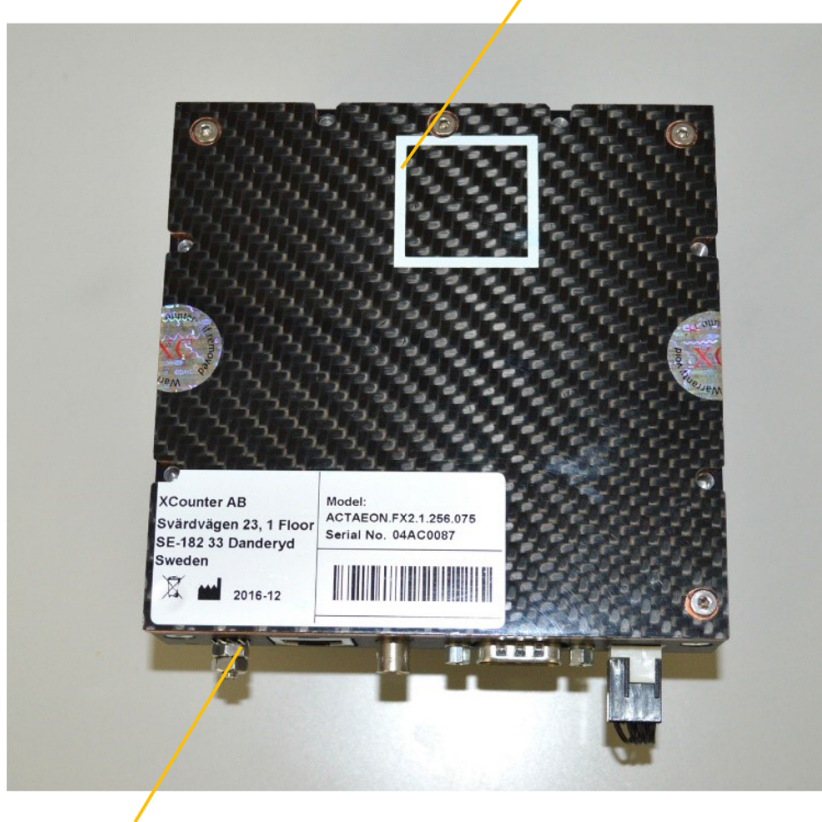

Ethernet port for power supply

Figure 1. Experimental setup for performing actual-dimension radiography using a DE CdTe array detector and a 0.1-mm-focus X-ray generator. General view of the DE CdTe array detector Actaeon is shown in the same figure.

Table 1. Various conditions in DE radiography using the CdTe array detector.

\begin{tabular}{cc}
\hline & Radiography \\
\hline Tube voltage $(\mathrm{kV})$ & 60 and 80 \\
Tube current $(\mathrm{mA})$ & 0.50 \\
Focus diameter $(\mathrm{mm})$ & 0.1 \\
Be-window thickness $(\mathrm{mm})$ & 0.5 \\
Al-filter thickness $(\mathrm{mm})$ & 1.0 \\
X-ray source to array distance $(\mathrm{m})$ & 1.00 \\
Object to array distance $(\mathrm{m})$ & 0 \\
Frame rate under photon-counting $(\mathrm{Hz})$ & 100 \\
Averaging-frame numbers per radiogram & 200 \\
Exposure time for an average image $(\mathrm{s})$ & 2.0 \\
\hline
\end{tabular}


Because the averaging-frame number per image (radiogram) is set to 200 to improve the image quality, the exposure time for DE radiography is $2.0 \mathrm{~s}$.

Various specifications are shown in Table 2. The dimensions of the CdTe array are $25 \times 25 \mathrm{~mm}^{2}$, and the detector is powered through an Ethernet port. The pixel dimensions are $0.1 \times 0.1 \mathrm{~mm}^{2}$, and each pixel has an individual charge-sensitive amplifier and a DE counter. In the photon-counting DE mode, the maximum frame rate is below $1 \mathrm{kfps}$. However, the maximum rate and the minimum capture time are $2.5 \mathrm{kfps}$ and $50 \mu \mathrm{s}$, respectively, in the piled-up single mode.

\subsection{Measurements of X-Ray Dose Rate and Spectra}

The measurement of X-ray dose rate is important to calculate incident dose for patients. The X-ray dose rate from the $\mathrm{X}$-ray generator was measured using an ionization chamber (Toyo Medic, RAMTEC 1000 plus) with the Al filtration at a tube current of $0.50 \mathrm{~mA}$. The chamber was placed $1.0 \mathrm{~m}$ from the X-ray source, and we measured the dose rate with changes in the tube voltage from 50 to $100 \mathrm{kV}$.

To measure X-ray spectra with changes in the tube voltage, we used a readily available CdTe detector (Amptek, XR100-T) with a 0.5-mm-diam lead pinhole placed $1.0 \mathrm{~m}$ from the X-ray source. The event pulses from the shaping amplifier are input to a multichannel analyzer (MCA; $\gamma \mathrm{PGT}, \mathrm{MCA} 4000$ ) to perform pulse-height analysis. The photon energy was determined by two-point calibration using $\mathrm{K} \alpha_{1}$ photon energies of tungsten (W; $\left.59.3 \mathrm{keV}\right)$ and $\mathrm{I}(28.6 \mathrm{keV})$.

\subsection{Real Animal Phantoms}

In the DE-CT, we used real dog-heart and rabbit-head phantoms. These phantoms were made approximately twenty years ago, and the operation on animals was carried out in accordance with the animal experiment guidelines of our university.

\section{Results}

\subsection{X-Ray Dose Rate and Spectra}

Figure 2 shows the $\mathrm{X}$-ray dose rate after penetrating the Al filter at a constant tube current of $0.50 \mathrm{~mA}$. X-ray dose rate increased with increasing tube voltage and

Table 2. Various specifications of the DE CdTe array detector Actaeon made by XCounter.

\begin{tabular}{cc} 
& Specifications \\
\hline Maker & XCounter \\
Type & Actaeon \\
CdTe array dimensions $\left(\mathrm{mm}^{2}\right)$ & $25 \times 25$ \\
CdTe pixel dimensions $\left(\mathrm{mm}^{2}\right)$ & $0.1 \times 0.1$ \\
Charge-amplifier number per $\mathrm{mm}^{2}$ & 100 \\
Mode & Single \& Dual (photon counting) \\
Minimum capture time under single mode $(\mu \mathrm{s})$ & 50 \\
Maximum frame rate under single mode $(\mathrm{kfps})$ & 2.5
\end{tabular}


was not proportional to the second power of the tube voltage. At tube voltages of 60 and $80 \mathrm{kV}$, the $\mathrm{X}$-ray dose rates were 52.7 and $78.8 \mu \mathrm{Gy} / \mathrm{s}$, respectively.

The X-ray spectra measured using the CdTe detector are show in Figure 3. The maximum photon energy increased with increasing tube voltage from 60 to $80 \mathrm{kV}$. At a tube voltage of $80 \mathrm{kV}$, we observed $\mathrm{W}-\mathrm{K}$ photons.

Figure 4 shows selected X-ray spectra for DE radiography using I media, and the $\mathrm{X}$-ray photons with energies ranging from 10 to $60 \mathrm{keV}$ are useless for carrying out I-K-edge radiography (Figure $4(\mathrm{a})$ ). On the contrary, the X-ray photons at a range of 33 - $60 \mathrm{keV}$ are useful for performing I-K-edge radiography (Figure 4(b)).

The selected X-ray spectra using Gd media are shown in Figure 5. Although

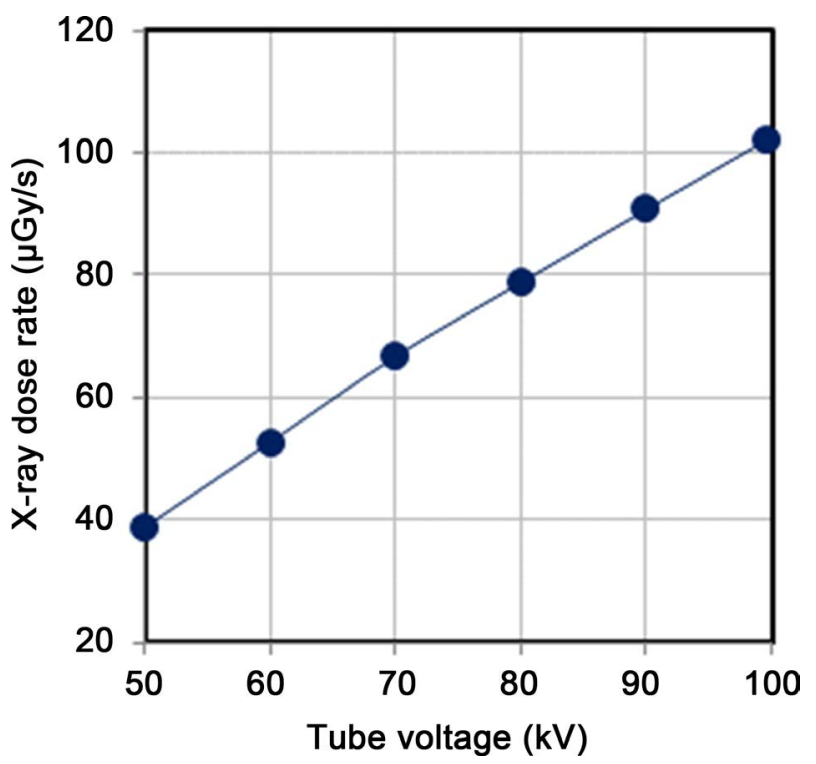

Figure 2. X-ray dose rate at $1.0 \mathrm{~m}$ from the X-ray source and a tube current of $0.50 \mathrm{~mA}$ using a $1.0-\mathrm{mm}$-thick $\mathrm{Al}$ filter.

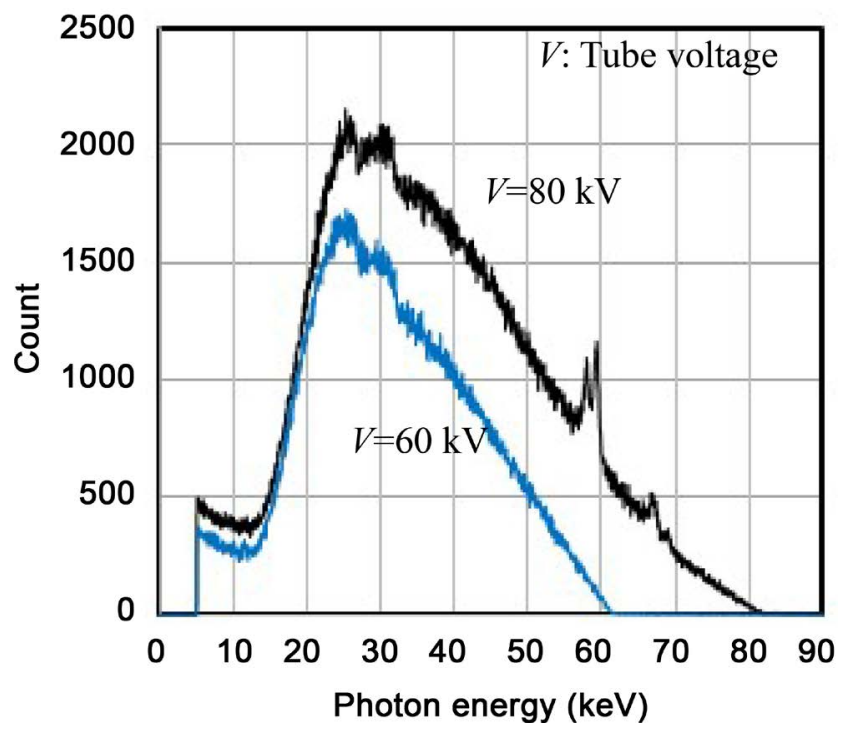

Figure 3. X-ray spectra measured using a readily available CdTe detector with changes in the tube voltage. 


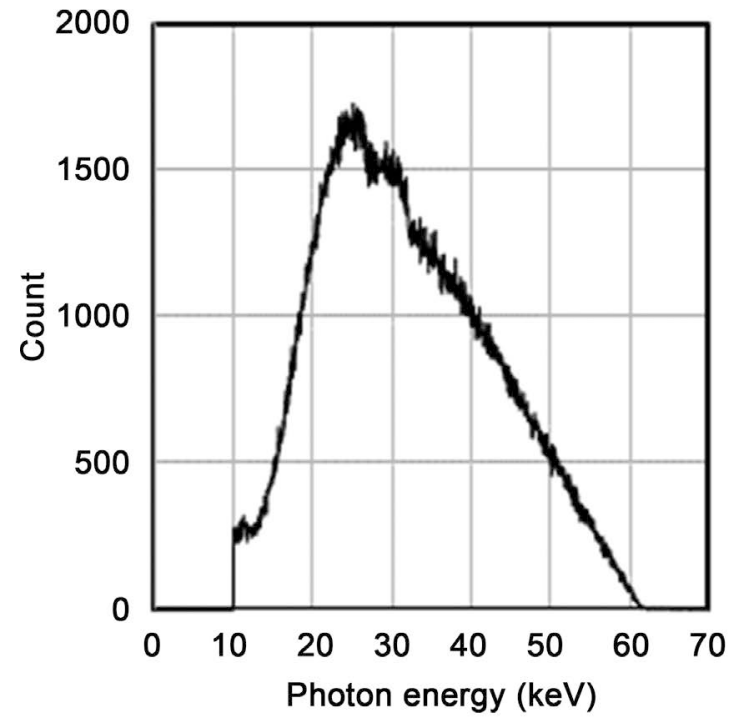

(a)

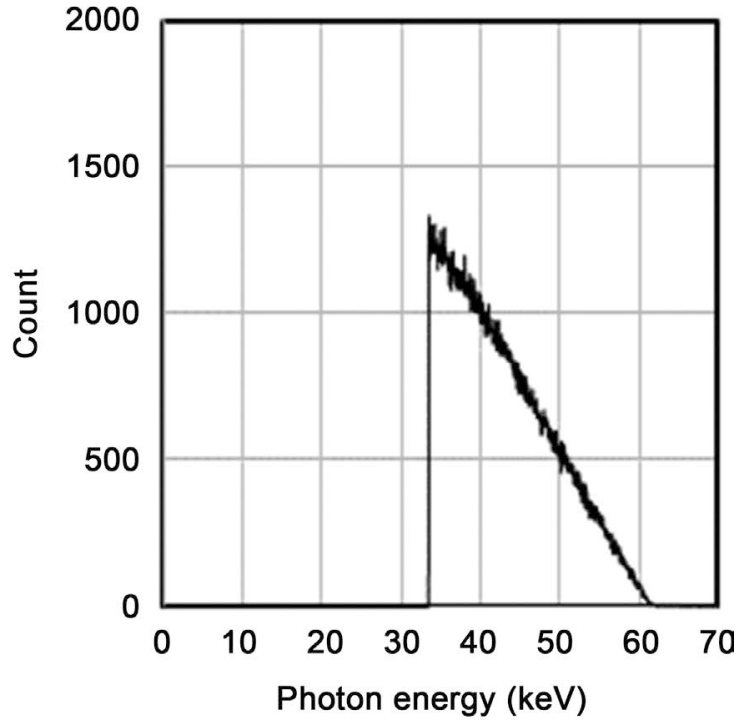

(b)

Figure 4. Selected X-ray spectra for DE radiography using I media. (a) X-ray photons at an energy range of 10 - 60 $\mathrm{keV}$ and (b) photons for I-K-edge radiography at a range of $33-60 \mathrm{keV}$.

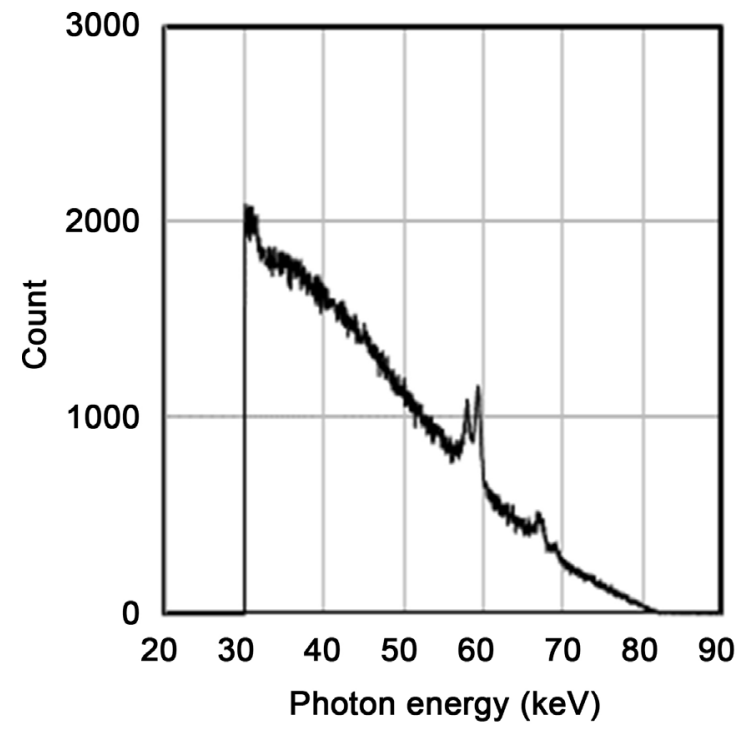

(a)

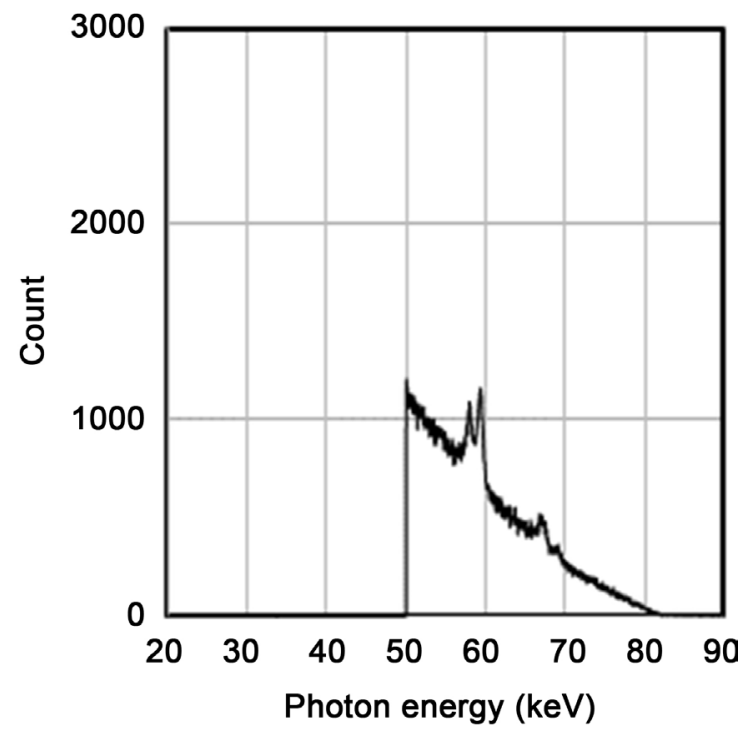

(b)

Figure 5. Selected X-ray spectra for DE radiography using Gd media. (a) X-ray photons at a range of $30-80 \mathrm{keV}$ and (b) photons for Gd-K-edge radiography at a range of $50-80 \mathrm{keV}$.

the X-ray photons beyond $30 \mathrm{keV}$ are not so useful for imaging Gd media (Figure 5(a)), the photons beyond $50 \mathrm{keV}$ are useful for performing Gd-K-edge radiography (Figure 5(b)).

\subsection{DE Radiography}

Radiography was performed at a constant tube current of $0.50 \mathrm{~mA}$. Radiograms are obtained as JPEG files, and the maximum and minimum gray-value densities are defined as 255 (white) and 0 (black), respectively.

Figure 6 shows radiography of two glass vials filled with two-different-density 
I media (iopamidol) of 15 and $30 \mathrm{mg} / \mathrm{ml}$. The gray-value-density analysis using a program of Image $J$ is shown in the same figure. At an energy range of $10-60$ $\mathrm{keV}$, it was easy to image glass walls, and the gray-value densities were almost the same. Utilizing I-K-edge radiography at a range of $33-60 \mathrm{keV}$, the density difference between the media increased, and the glass walls were not so visible.

Radiography (angiography) of a dog-heart phantom is shown in Figure 7, and the coronary arteries are filled with I-based microspheres of $15 \mu \mathrm{m}$ in diameter. At a range of $10-60 \mathrm{keV}$, the muscle density was low, and the arteries were not visible. When the energy range was increased to $33-60 \mathrm{keV}$, the muscle density increased, and the arteries were observed at high contrasts.

Figure 8 shows radiography of two glass vials filled with Gd media (meglumine

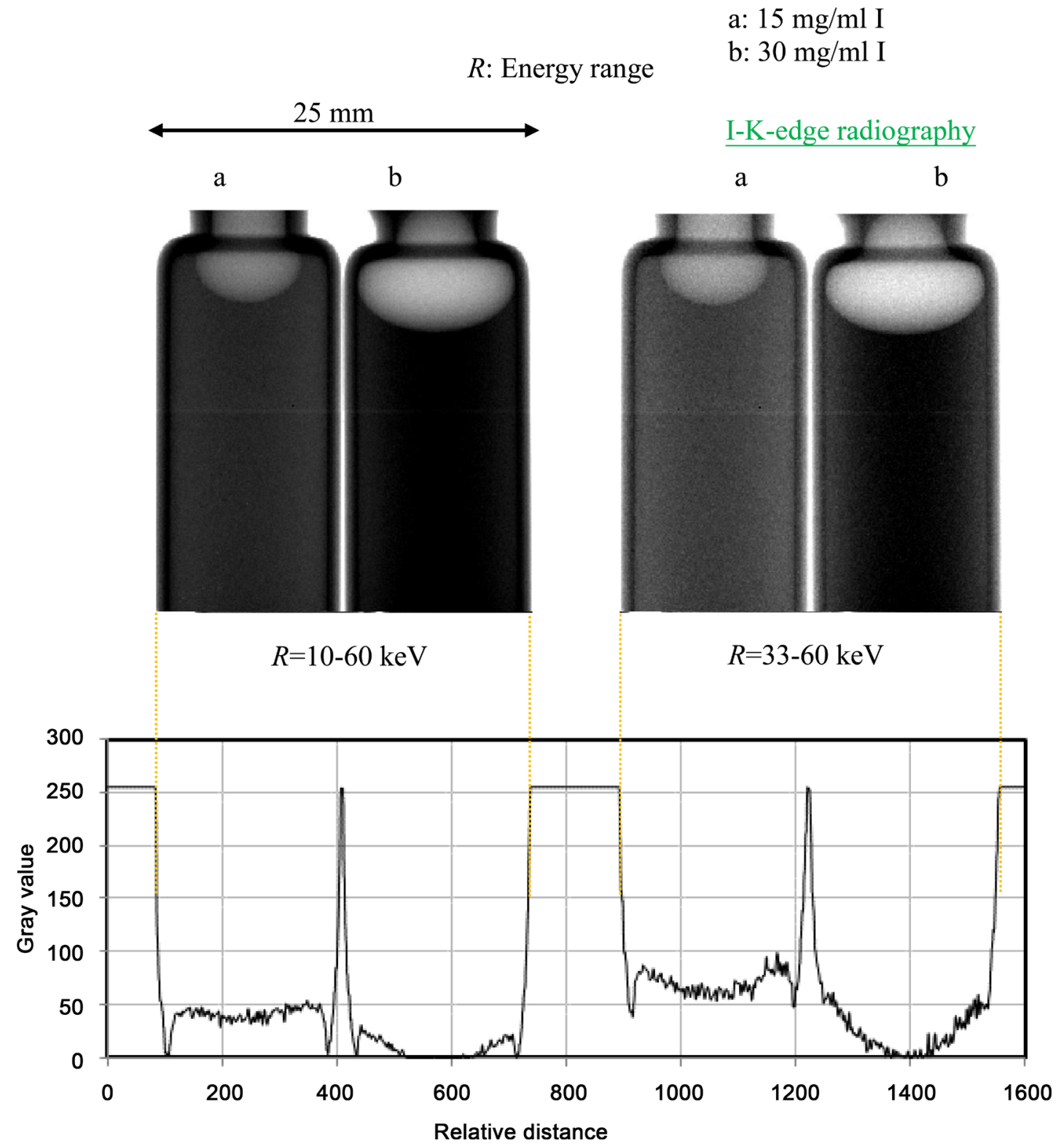

Figure 6. DE radiography of two glass vials filled with two I media of two different densities of 15 and $30 \mathrm{mg} / \mathrm{ml}$. The image density difference between the two media increased with increases in the energy range. 


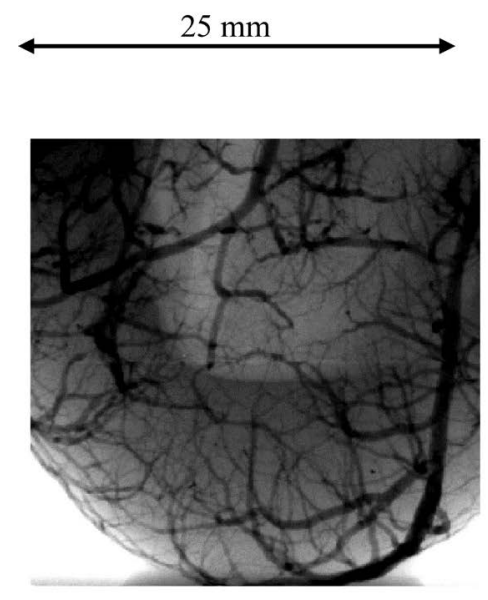

$R=10-60 \mathrm{keV}$

\section{$R$ : Energy range}

I-K-edge radiography

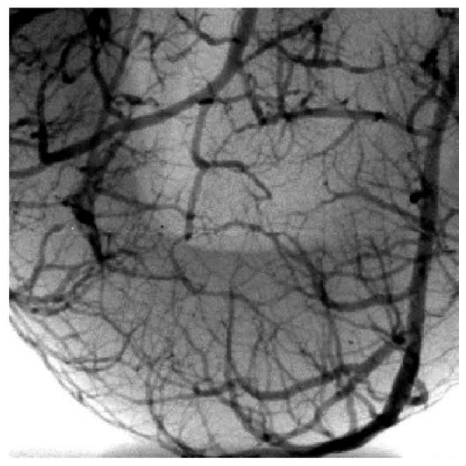

$R=33-60 \mathrm{keV}$

Figure 7. DE radiography of a dog-heart phantom. When the energy range increased, the muscle density increased, and the arteries were observed at high contrasts.

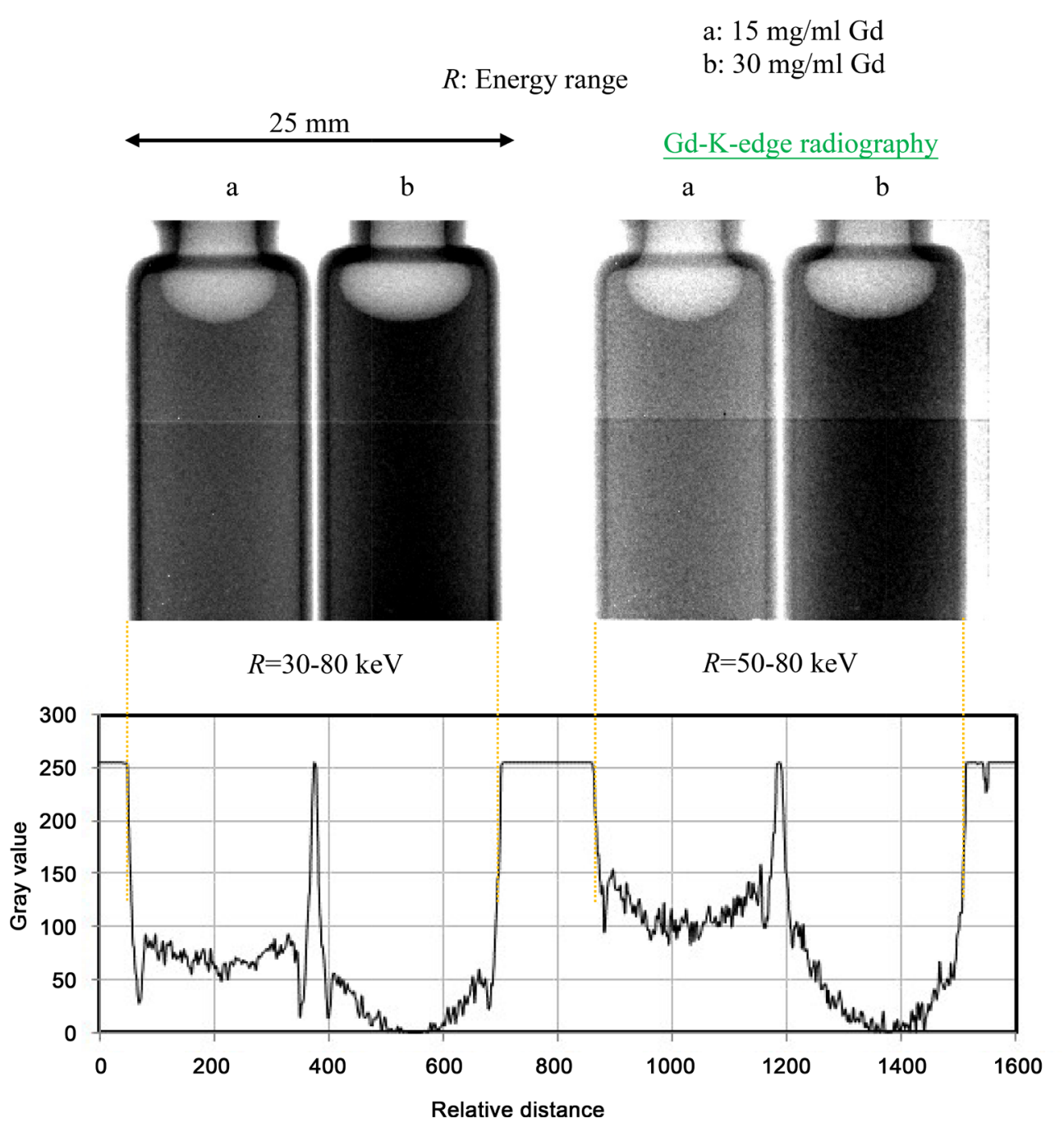

Figure 8. DE radiography of two glass vials filled with two Gd media of two different densities of 15 and $30 \mathrm{mg} / \mathrm{ml}$. The image density difference between the two media increased with increasing energy range. 
gadopentetate) of two different densities of 15 and $30 \mathrm{mg} / \mathrm{ml}$. At a range of 30 $80 \mathrm{keV}$, the image density decreased slightly with increasing Gd density, and it was easy to image glass walls. Next, utilizing Gd-K-edge CT at a range of $50-80$ $\mathrm{keV}$, the density substantially decreased with increasing Gd density, and it was difficult to image the glass walls.

Radiography of a rabbit-head phantom is shown in Figure 9, and blood vessels are filled with gadolinium oxide $\left(\mathrm{Gd}_{2} \mathrm{O}_{3}\right)$ microparticles of $1-10 \mu \mathrm{m}$ in diameter. At a range of $30-80 \mathrm{keV}$, the muscle density was low, and it was difficult to image the vessels in the nose clearly. When the energy range was increased to $50-80 \mathrm{keV}$, the muscle density increased, and the vessels were observed at high contrasts.

\section{Discussion}

We used a DE CdTe array detector with the array and pixel dimensions of $25 \times$ $25 \mathrm{~mm}^{2}$ and $0.1 \times 0.1 \mathrm{~mm}^{2}$, respectively. The array consists of $6.25 \times 10^{4}$ pixels, and it was difficult to determine the total energy resolution of the array detector. However, the energy resolution of the array detector was below $50 \%$ at $59.5 \mathrm{keV}$ compared with the former results obtained using several first-generation ED-CT scanners.

To improve the image granulation owing to low-count rates, we performed the averaging radiography using 200 frames at an X-ray exposure times of $2.0 \mathrm{~s}$. However, the exposure time can be reduced to approximately $0.1 \mathrm{~s}$ or less by increasing the tube current, reducing the distance between the source and the

\section{$R$ : Energy range}

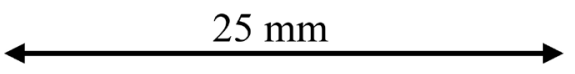

\section{Gd-K-edge radiography}

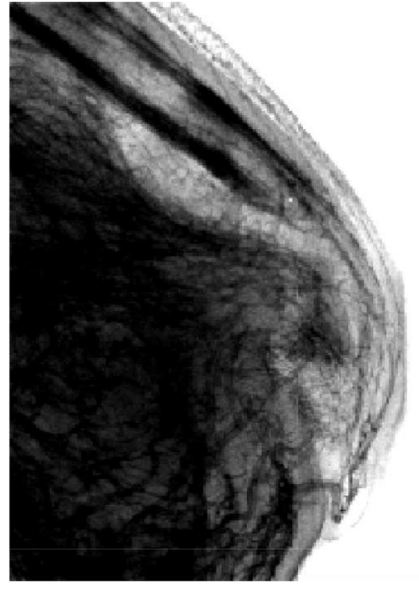

$$
R=30-80 \mathrm{keV}
$$

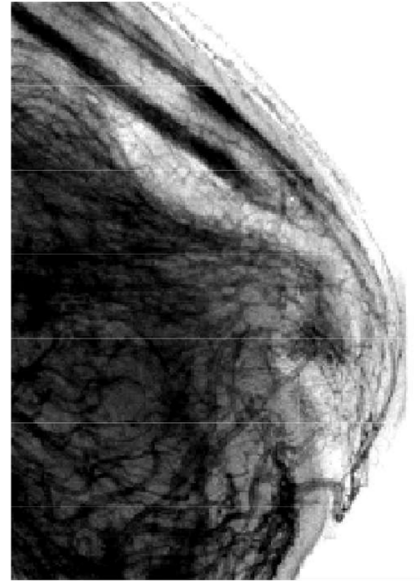

Figure 9. DE radiography of a rabbit-head phantom. When the energy range increased, the muscle density increased, and the blood vessels in the nose were observed at high contrasts. 
detector, decreasing the frame number, and increasing the frame rate to $0.5 \mathrm{kfps}$.

In the $\mathrm{DE}$ array detector, only two threshold energies can be selected, and two energy ranges can be used at a constant photon energy corresponding to the tube voltage. Generally, it is difficult to confirm the contrast variations with changes in the threshold energy, and a photon-count energy-subtraction program is desired to demonstrate the DE effect. In the present work, although we performed DE radiography of four phantoms, the energy resolution of the DE array should be improved.

In radiography, we carried out gray-value density analysis utilizing Image J, and the contrast resolutions of radiograms are regulated to the maximum value of approximately 1 . Therefore, the contrast variations were observed at maximum contrasts, and comparatively quantitative image analysis was performed.

Compared with conventional flat panel detectors, the advantages are as follows; the sensitivity is high, the image contrast varies without changes in the tube voltage, and monochromatic imaging can be performed. On the contrary, the disadvantages are as follows; the pileup of the event pulses is caused by increasing photon-count rate, high-speed energy-range selectors are desired, and the electric circuit for one CdTe pixel is quite complex.

Since we used a 0.1-mm-focus X-ray tube, the magnification ratio can be increased to approximately 2 , and the spatial resolutions can also be improved to $50 \times 50 \mu \mathrm{m}^{2}$. In addition, DE-embossed radiography utilizing general energy subtraction [12] might be useful for increasing the contrast resolution up to 1.0.

\section{Conclusion}

We performed photon-counting DE radiography using a CdTe array detector with spatial resolutions of $0.1 \times 0.1 \mathrm{~mm}^{2}$, and K-edge radiography using I and Gd media was carried out. The energy ranges for I- and Gd-K-edge radiography were $33-50$ and $50-80 \mathrm{keV}$, respectively. Actual-dimension radiography was carried out, and we confirmed the image contrast variations with changes in the energy range.

\section{Acknowledgements}

This work was supported by Grants from Keiryo Research Foundation, Promotion and Mutual Aid Corporation for Private Schools of Japan, Japan Science and Technology Agency (JST), and JSPS KAKENHI (17K10371, 17K09068, 17K01424, 17H00607). This was also supported by a Grant-in-Aid for Strategic Medical Science Research (S1491001, 2014-2018) from the Ministry of Education, Culture, Sports, Science and Technology of Japan.

\section{References}

[1] Mori, H., Hyodo, K., Tanaka, E., Uddin-Mohammed, M., Yamakawa, A., Shinozaki, Y., Nakazawa, H., Tanaka, Y., Sekka, T., Iwata, Y., Handa, S., Umetani, K., Ueki, H., Yokoyama, T., Tanioka, K., Kubota, M., Hosaka, H., Ishikawa, N. and Ando, M. (1996) Small-Vessel Radiography in Situ with Monochromatic Synchrotron Radia- 
tion. Radiology, 201, 173-177. https://www.ncbi.nlm.nih.gov/pubmed/8816540 https://doi.org/10.1148/radiology.201.1.8816540

[2] Hyodo, K., Ando, M., Oku, Y., Yamamoto, S., Takeda, T., Itai, Y., Ohtsuka, S., Sugishita, Y. and Tada, J. (1998) Development of a Two-Dimensional Imaging System for Clinical Applications of Intravenous Coronary Angiography Using Intense Synchrotron Radiation Produced by a Multipole Wiggler. Journal of Synchrotron Radiation, 5, 1123-1126. https://www.ncbi.nlm.nih.gov/pubmed/15263766 https://doi.org/10.1107/S0909049597017639

[3] Sato, E., Tanaka, E., Mori, H., Kawai, T., Ichimaru, T., Sato, S., Takayama, K. and Ido, H. (2004) Demonstration of Enhanced K-Edge Angiography Using a Cerium Target X-Ray Generator. Medical Physics, 31, 3017-3022.

https://www.ncbi.nlm.nih.gov/pubmed/15587654 https://doi.org/10.1118/1.1803433

[4] Watanabe, M., Sato, E., Abderyim, P., Abudurexiti, A., Hagiwara, O., Matsukiyo, H., Osawa, A., Enomoto, T., Nagao, J., Sato, S., Ogawa, A. and Onagawa, J. (2011) First Demonstration of $10 \mathrm{keV}$-Width Energy-Discrimination K-Edge Radiography Using a Cadmium-Telluride X-Ray Camera with a Tungsten-Target Tube. Nuclear Instruments and Methods in Physics Research Section A, 637, 171-177. http://www.sciencedirect.com/science/article/pii/S0168900211004098

[5] Yanbe, Y., Sato, E., Chiba, H., Maeda, T., Matsushita, R., Oda, Y., Hagiwara, O., Matsukiyo, H., Osawa, A., Enomoto, T., Watanabe, M., Kusachi, S., Sato, S. and Ogawa, A. (2013) High-Sensitivity High-Speed X-Ray Fluorescence Scanning Cadmium Telluride Detector for Deep-Portion Cancer Diagnosis Utilizing Tungsten-Ka-Excited Gadolinium Mapping. Japanese Journal of Applied Physics, 52, 092201-1-4. http://iopscience.iop.org/article/10.7567/JJAP.52.092201/meta https://doi.org/10.7567/JJAP.52.092201

[6] Hagiwara, O., Sato, E., Watanabe, M., Sato, Y., Oda, Y., Matsukiyo, H., Osawa, A., Enomoto, T., Kusachi, S. and Ehara, S. (2014) Investigation of Dual-Energy X-Ray Photon Counting Using a Cadmium Telluride Detector and Two Comparators and Its Application to Photon-Count Energy Subtraction. Japanese Journal of Applied Physics, 53, 102202-1-6. http://iopscience.iop.org/article/10.7567/JJAP.53.102202 https://doi.org/10.7567/JJAP.53.102202

[7] Sato, E., Kosuge, Y., Yamanome, H., Mikata, A., Miura, T., Oda, Y., Ishii, T., Hagiwara, O., Matsukiyo, H., Watanabe, M. and Kusachi, S. (2017) Investigation of Dual-Energy X-Ray Photon Counting Using a Cadmium Telluride Detector with Dual-Energy Selection Electronics. Radiation Physics and Chemistry, 130, 385-390. https://www.sciencedirect.com/science/article/pii/S0969806X1630367X https://doi.org/10.1016/j.radphyschem.2016.09.018

[8] Matsukiyo, H., Sato, E., Oda, Y., Ishii, T., Yamaguchi, S., Sato, Y., Hagiwara, O., Enomoto, T., Watanabe, M. and Kusachi, S. (2017) Investigation of Quad-Energy Photon Counting for X-Ray Computed Tomography Using a Cadmium Telluride Detector. Applied Radiation and Isotopes, 130, 54-59. https://www.sciencedirect.com/science/article/pii/S0969804317305146 https://doi.org/10.1016/j.apradiso.2017.09.011

[9] Feuerlein, S., Roessl, E., Proksa, R., Martens, G., Klass, O., Jeltsch, M., Rasche, V., Brambs, H.J., Hoffmann, M.H.K. and Schlomka, J.P. (2008) Multienergy Photon-Counting K-Edge Imaging: Potential for Improved Luminal Depiction in Vascular Imaging. Radiology, 249, 1010-1016.

http://pubs.rsna.org/doi/abs/10.1148/radiol.2492080560

https://doi.org/10.1148/radiol.2492080560 
[10] Ogawa, K., Kobayashi, T., Kaibuki, F., Yamakawa, T., Nanano, T., Hashimoto, D. and Nagaoka, H. (2012) Development of an Energy-Binned Photon-Counting Detector for X-Ray and Gamma-Ray Imaging. Nuclear Instruments and Methods in Physics Research Section A, 664, 29-37.

http://www.sciencedirect.com/science/article/pii/S0168900211018997 https://doi.org/10.1016/j.nima.2011.10.009

[11] Zscherpel, U., Walter, D., Redmer, B., Ewert, U., Ullberg, C., Weber, N. and Pantsar, T. (2014) Digital Radiology with Photon Counting Detectors. Proceedings of 11 th European Conference on Non-Destructive Testing, Prague, 6-10 October 2014, 1-8. http://www.ndt.net/events/ECNDT2014/app/content/Paper/461_Zscherpel.pdf

[12] Osawa, A., Watanabe, M., Sato, E., Matsukiyo, H., Enomoto, T., Nagao, J., Abderyim, P., Aizawa, K., Tanaka, E., Mori, H., Kawai, T., Ogawa, A., Takahashi, K., Sato, S. and Onagawa, J. (2010) Magnification Embossed Radiography Utilizing Image-Shifting Subtraction Program. Japanese Journal of Applied Physics, 49, 037001-1-7.

http://iopscience.iop.org/article/10.1143/JJAP.49.037001

https://doi.org/10.1143/JJAP.49.037001 